\title{
O impacto do Programa Minha Casa, Minha Vida na economia brasileira: uma análise de insumo- produto
}

The impact of the "My House, My Life" Housing Program in the Brazilian economy: an analysis of input-output

Carlos Alberto Gonçalves Junior Universidade Estadual do Oeste do Toledo - PR - Brasil

Ricardo de Lemos Dutra Universidade Estadual do Oeste do Paraná Toledo - PR - Brasil

Ricardo Luis Lopes Universidade Estadual de Maringá Maringá - PR - Brasil

Rossana Lott Rodrigues Universidade Estadual de Londrina Londrina - PR - Brasil

Recebido em 14/09/13 Aceito em 11/02/14

\section{Carlos Alberto Gonçalves Junior Ricardo de Lemos Dutra Ricardo Luis Lopes Rossana Lott Rodrigues}

\section{Resumo}

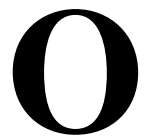

objetivo do presente artigo foi analisar o impacto do Programa Habitacional Minha Casa, Minha Vida na economia brasileira mediante a dinamização do setor da construção civil, utilizando a matriz de insumo-produto de 2008 para estimação dos geradores e multiplicadores de produção, renda, emprego e impostos. Os resultados mostraram que o setor da construção civil apresentou ligações para trás e para frente abaixo da média dos setores da economia. No entanto, considerando o valor de $\mathrm{R} \$ 125,7$ bilhões previstos para investimento no período em análise, constatou-se que haverá crescimento significativo na renda paga aos trabalhadores, serão criados cerca de 7 milhões de empregos diretos e indiretos, haverá aumento na produção de cerca de $6 \%$ do PIB em valores de 2010, e pelo menos $16 \%$ do valor dos subsídios dados nos contratos de financiamento do PMCMV voltarão aos cofres públicos.

Palavras-chave: Insumo-produto. Construção civil. Déficit habitacional. Programa Minha Casa, Minha Vida.

\section{Abstract}

The aim of this paper is to analyze the impact of the "My House, My Life" Housing Program in the Brazilian economy through the dynamic of the construction industry. The input-output matrix was used to estimate the generators and multipliers of production, income, employment and taxes. The results indicated that the construction industry had forward and backwards links below the average of the economy sectors. However, considering the amount of $R \$ 125,7$ billions planned for investment in the period under review, the conclusion was made that there will be a meaningful increase in workers' income, 7 millions of direct and indirect jobs will be created, there will be an approximate $6 \%$ increase in the production of GDP in 2010 figures and, at least, $16 \%$ of the subsides offered in the financing contracts of this program will return to the Government.

Keywords: Input-output. Construction. Housing deficit. My House My Life Program. 


\section{Introdução}

O Programa Minha Casa, Minha Vida (PMCMV) é um programa do Governo Federal destinado, principalmente, às famílias de baixa renda, gerido pelo Ministério das Cidades e operacionalizado pela Caixa Econômica Federal (Caixa). Consiste na aquisição de terreno e na construção de unidades habitacionais que, depois de concluídas, são destinadas ${ }^{1}$ a famílias (BRASIL, 2009).

Entre as diretrizes básicas do programa está a redução do déficit habitacional, que, de acordo com o Ministério das Cidades, em 2008 já superava os cinco milhões de residências, estando $89 \%$ do déficit entre famílias que auferem renda de até três salários mínimos. Outras diretrizes básicas do programa são a dinamização do setor de construção civil e a geração de emprego e renda (MINISTÉRIO..., 2011).

Nesse contexto, sem abordar questões meritórias do referido programa, o presente artigo tem como objetivo analisar o impacto do PMCMV na economia brasileira, utilizando a metodologia de insumo-produto através dos multiplicadores de produção, emprego e renda. Além disso, busca identificar a proporção do retorno aos cofres públicos dos subsídios dados aos financiamentos, pelo multiplicador dos impostos.

Para atender ao objetivo proposto, o artigo está dividido em seis seções, incluindo a introdução. A segunda define o conceito de déficit habitacional no Brasil, bem como levanta informações acerca dele. A terceira seção traz informações do PMCMV. Na quarta seção são apresentados os conceitos e os números do setor da construção civil. Na quinta seção é apresentada a metodologia insumo-produto, utilizada no artigo, conceitos de setor-chave, geradores e multiplicadores. A sexta seção traz os resultados e discussões, e a sétima, as conclusões.

\section{Déficit habitacional}

Trabalhos como os de Vasconcelos e Cândido Junior (1996), Gonçalves (1998), Ferreira (2004) e Ministério das Cidades (2011) discutem a mensuração e o problema específico do déficit habitacional. No entanto, como essa discussão não é o foco do presente artigo, será abordado aqui somente o conceito de déficit habitacional aceito pelo Ministério das Cidades, que toma como base a metodologia da Fundação João Pinheiro (FJP).

\footnotetext{
${ }^{1}$ Maiores detalhes sobre as prerrogativas do programa podem ser consultados nos seguintes sites:

http://www.caixa.gov.br/habitacao/mcmv/ e

http://www.cidades.gov.br/index.php/minha-casa-minha-vida.
}

Segundo o Ministério das Cidades (2011), o conceito de déficit habitacional está ligado diretamente às deficiências do estoque de moradias. Engloba aquelas sem condições de ser habitadas e que devem ser repostas, incluindo ainda a necessidade de incremento do estoque de moradias em função da coabitação familiar forçada (casos em que mais de uma família mora na mesma casa), o adensamento excessivo (quando mais de três pessoas dividem o mesmo quarto) ou ônus excessivo de aluguel (quando uma família compromete mais de $30 \%$ de sua renda com aluguel).

Desse modo, o déficit habitacional pode ser entendido como déficit por reposição de estoque e déficit por incremento de estoque. $\mathrm{O}$ primeiro caso refere-se aos domicílios rústicos, aos quais deveria ser acrescida parcela proveniente de sua depreciação, em decorrência de suas condições de insalubridade. Esse tipo de edificação proporciona desconforto e traz risco de contaminação por doenças. Já o déficit por incremento de estoque contempla os domicílios improvisados, coabitação familiar forçada e dois tipos de domicílios alugados: os fortemente adensados e aqueles em que famílias pobres (renda familiar de até três salários mínimos) pagam $30 \%$ ou mais de sua renda para o locador.

Para estimar o déficit habitacional, Furtado, Lima Neto e Krause (2013) utilizam dados da Pesquisa Nacional por Amostra de Domicílios (PNAD). No período 2007 a 2011 houve uma queda no déficit habitacional de $10,0 \%$ para $8,8 \%$ dos domicílios particulares permanentes. Quando se considera apenas a área urbana, o déficit caiu de $9,69 \%$ para $8,55 \%$, e na área rural a queda foi de $11,76 \%$ para 10,43\%, conforme a Tabela 1.

De acordo com a Tabela 2, a região com maior déficit habitacional no Brasil em 2011 foi a Norte, com 13,07\%, seguida da Nordeste, com 11,57\%. Já o menor déficit habitacional foi observado na Região Sul, 6,11\%. A região que mais reduziu percentualmente o déficit habitacional, no período analisado, foi a Nordeste, enquanto o Centro-Oeste foi a única que não conseguiu reduzi-lo.

Gonçalves (1998) observou que o déficit habitacional atinge, com maior intensidade, as famílias de renda mais baixa, conclusões corroboradas por Furtado, Lima Neto e Krause (2013).

Observando a Tabela 3 é possível verificar que as famílias de baixa renda são as que mais sofrem com o déficit habitacional, com destaque para a 
faixa de renda de até 3 salários mínimos, em que o déficit chegou a 70,6\% no ano de 2011.

Nesse contexto, tendo a redução do déficit habitacional como um de seus objetivos, em julho 2009, através da Lei 11.977, o Governo Federal criou o Programa Minha Casa, Minha Vida (PMCMV), principalmente para atender às famílias nas faixas mais baixas de renda, que, de acordo com a Tabela 3, são as mais penalizadas pelo déficit habitacional. Esse programa será detalhado na próxima seção.

\section{Programa Minha Casa, Minha Vida}

As diretrizes básicas do PMCMV são: redução do déficit habitacional; distribuição de renda e inclusão social; e dinamização do setor de construção civil e geração de trabalho e renda (BRASIL, 2011).
O PMCMV tem por finalidade criar mecanismos de incentivo à produção e aquisição de novas unidades habitacionais para famílias com renda mensal bruta de até $\mathrm{R} \$ 4.650,00$ e compreende dois subprogmas: o Programa Nacional da Habitação Urbana (PNHU); e o Programa Nacional da Habitação Rural (PNHR) (BRASIL, 2009).

Apesar de se destinar a famílias de renda mensal bruta de até $\mathrm{R} \$ 4.650,00$ (dez salários mínimos em 2009), a prioridade é dada para famílias com renda mensal bruta de até $\mathrm{R} \$ 1.395,00$ (três salários mínimos em 2009), para as quais a maior parte dos recursos é destinada.

O programa utiliza recursos do Fundo de Garantia por Tempo de Serviço (FGTS), do Fundo de Arrendamento Residencial (FAR) e do Fundo de Desenvolvimento Social (FDS). É gerido pelo Ministério das Cidades e operacionalizado pela Caixa Econômica Federal (Caixa).

Tabela 1 - Déficit Habitacional e percentual em relação aos domicílios particulares permanentes, urbano, rural e média nacional, Brasil, 2007-2011

\begin{tabular}{c|c|c|c|c|c}
\hline \multirow{2}{*}{ Ano } & \multicolumn{2}{|c|}{$\begin{array}{c}\text { Déficit habitacional } \\
\text { valores absolutos }\end{array}$} & \multicolumn{3}{c}{$\begin{array}{c}\text { Percentual em relação aos domicílios } \\
\text { particulares permanentes }\end{array}$} \\
\cline { 2 - 6 } & Urbano & Rural & Urbano & Rural & Média Geral \\
\hline 2007 & 4.607 .176 & 986.015 & $9,69 \%$ & $11,76 \%$ & $10,00 \%$ \\
2008 & 4.278 .033 & 913.532 & $8,71 \%$ & $10,62 \%$ & $9,00 \%$ \\
2009 & 4.791 .825 & 911.178 & $9,58 \%$ & $10,55 \%$ & $9,72 \%$ \\
2011 & 4.548 .545 & 860.665 & $8,55 \%$ & $10,43 \%$ & $8,80 \%$ \\
\hline
\end{tabular}

Fonte: Furtado, Lima Neto e Krause (2013) utilizando dados das PNADs.

Tabela 2- Déficit habitacional percentual em relação aos domicílios particulares permanentes por Região, Brasil, 2007-2011

\begin{tabular}{c|c|c|c|c|c}
\hline Ano & Norte & Nordeste & Sudeste & Sul & Centro-Oeste \\
\hline 2007 & 14,38 & 13,58 & 8,47 & 7,07 & 8,83 \\
2008 & 12,69 & 12,15 & 7,52 & 6,18 & 9,12 \\
2009 & 14,07 & 12,69 & 8,23 & 6,40 & 10,81 \\
2011 & 13,07 & 11,57 & 7,22 & 6,11 & 9,66 \\
\hline
\end{tabular}

Fonte: Furtado, Lima Neto e Krause (2013) utilizando dados das PNADs.

Tabela 3 - Distribuição percentual do déficit habitacional urbano, por faixas de renda média domiciliar ${ }^{1}$ mensal, Brasil, 2007-2011

\begin{tabular}{c|c|c|c|c}
\hline \multirow{2}{*}{ Ano } & \multicolumn{4}{|c}{ Faixas de renda mensal familiar (em salários mínimos) } \\
\cline { 2 - 5 } & até 3 & mais de 3 a 5 & mais de 5 a 10 & mais de 10 \\
\hline 2007 & 70,7 & 13,1 & 10,4 & 5,7 \\
2008 & 65,1 & 13 & 9,5 & 5,2 \\
2009 & 72,6 & 13,8 & 9,7 & 5,8 \\
2011 & 70,6 & 11,3 & 8,8 & 6 \\
\hline
\end{tabular}

Fonte: Furtado, Lima Neto e Krause (2013) utilizando dados das PNADs.

Nota: ${ }^{1} \mathrm{~A}$ Fundação João Pinheiro refere-se à renda familiar em vez de renda domiciliar. Com isso, chega-se a números de outra ordem de grandeza. Por exemplo, o déficit até 3 salários mínimos chega a $90 \%$. 
A abrangência do Programa prevê a contratação de empreendimentos localizados nas capitais estaduais e respectivas regiões metropolitanas, região metropolitana de Campinas/SP e da Baixada Santista/SP, Distrito Federal e municípios com população igual ou superior a 50 mil habitantes.

De acordo com UN-Habitat (2013), mais de $40 \%$ dos contratos firmados pelo PMCMV no período 2009-2010 ocorreram em cidades médias, com população entre 100 e 250 mil habitantes. As cidades médias têm características importantes para o sucesso do programa, como demanda por residências, disponibilidade de terrenos a preços mais acessíveis, além de possuir o setor da construção civil relativamente bem estruturado. Nesse cenário, pode-se considerar que o PMCMV estimula a economia não só nas grandes cidades, o que contribui para a descentralização do crescimento.

De acordo com a Tabela 4, nos anos de 2009 e 2010 o PMCMV superou a marca de um milhão de unidades habitacionais contratadas, considerando todas as modalidades do programa, sendo a maioria no Grupo 1, isto é, para os habitantes com menor renda, no qual reside o maior percentual do déficit habitacional.

Em todas as modalidades citadas, são financiadas apenas residências novas (primeiro habite-se), justamente para estimular o setor da construção civil e, consequentemente, a economia do país.

Segundo Magalhães (2011), está previsto para o período 2011 a 2014 o investimento total de R\$ 125,7 bilhões, sendo $42 \%$ destinados para financiamentos e o restante liberado na forma de subsídios. Com esse montante espera-se construir mais de dois milhões de novas moradias, $60 \%$ delas destinadas a famílias de baixa renda.

Ante o exposto, o presente artigo não tem como foco principal mostrar os benefícios sociais do programa no que tange à redução do déficit habitacional. $\mathrm{O}$ trabalho propõe-se a analisar o impacto do PMCMV na economia nacional pelo incremento na demanda ocorrido no setor da construção civil e estimar o transbordamento desse incremento para os outros setores da economia. Para isso, anteriormente, faz-se necessáriaa exposição de alguns dados sobre o referido setor.

\section{Setor da construção civil}

O setor da construção civil, de acordo com o Código Nacional de Atividade Econômica -Cnae 2.0 (IBGE, 2007), compreende a incorporação, compra e venda de imóveis, construção de edificações residenciais, industriais, comerciais e de serviços, além de construções de infraestrutura, como obras viárias, redes de abastecimento, portos e outros.

A construção civil é um setor vital por proporcionar a infraestrutura pública (portos, aeroportos, pontes, estradas, ferrovias e outras) e também a privada, necessária para o funcionamento de outras indústrias, comércio e serviços, além de poder ser utilizada como ferramenta de política pública para a criação de empregos em períodos de recessão (POLENSKE; SIVITANIDES, 1989).

Segundo Teixeira, Gomes e Silva (2011), o setor da construção civil é considerado de grande importância para qualquer economia mundial, principalmente pelo tamanho de seu produto como proporção do produto total da economia. Nos EUA, o setor contribuiu, no ano 2000, com $9 \%$ do produto interno bruto (PIB) do país; na União Europeia (para a média dos países-membros), esse percentual foi de $10 \%$; e na China, o setor chegou a $20 \%$ do PIB para o mesmo ano.

No Brasil, para Teixeira e Carvalho (2005), o setor da construção civil em 2003 participou com 7,23\% para a formação do PIB nacional e movimentou mais de $\mathrm{R} \$ 100$ bilhões, descontados os impostos indiretos líquidos e as margens de transporte e comercialização.

De acordo com a Pesquisa Anual da Indústria da Construção (Paic) realizada pelo Instituto Brasileiro de Geografia e Estatística (IBGE), em 2009 havia cerca de 64 mil empresas ativas com uma ou mais pessoas ocupadas na indústria da construção, empregando mais de 2 milhões de pessoas. $\mathrm{O}$ gasto com pessoal ocupado atingiu o valor de $\mathrm{R} \$ 48,3$ bilhões de reais, dos quais $\mathrm{R} \$$ 31,8 bilhões foram em pagamentos de salários, retiradas e outras remunerações, conforme mostra a Tabela 5 .

Tabela 4 - Unidades habitacionais contratadas e montante financiado pelo PMCMV, Brasil, 2009-2010

\begin{tabular}{l|c|c|c|c|c|c}
\hline & Grupo 1 & & Grupo 2 & & Grupo 3 & \\
\cline { 2 - 7 } & 0-3 sal min & \% & 3-6 sal min & \% & 6-10 sal min & \% \\
\hline Unidades construídas & 571.332 & $56,9 \%$ & 287.165 & $28,6 \%$ & 145.760 & $14,5 \%$ \\
Total financiado $(\mathrm{R} \$ 1.000)$ & 23.708 .569 & $44,7 \%$ & 20.309 .665 & $38,3 \%$ & 9.009 .518 & $17,0 \%$ \\
\hline
\end{tabular}

Fonte: UN-HABITAT (2013).

180 Gonçalves Junior, C. A.; Dutra, R. de L.; Lopes, R. L.; Rodrigues, R. L. 
Tabela 5 - Dados gerais da indústria da construção, Brasil 2008-2009

\begin{tabular}{|c|c|c|c|c|c|c|c|c|c|}
\hline \multirow[t]{2}{*}{ Ano } & $\begin{array}{c}\text { Núm. } \\
\text { empresas } \\
\text { ativas }\end{array}$ & $\begin{array}{c}\text { Pessoal } \\
\text { ocupado }\end{array}$ & $\begin{array}{c}\text { Salários, } \\
\text { retiradas e } \\
\text { outras } \\
\text { remunerações }\end{array}$ & $\begin{array}{c}\text { Gastos } \\
\text { com } \\
\text { pessoal }\end{array}$ & $\begin{array}{l}\text { Total de } \\
\text { custos e } \\
\text { despesas }\end{array}$ & $\begin{array}{l}\text { Valor das } \\
\text { incorporações } \\
\text { obras e/ou } \\
\text { serviços }\end{array}$ & $\begin{array}{c}\text { Valor } \\
\text { das } \\
\text { obras } \\
\text { e/ou } \\
\text { serviços }\end{array}$ & $\begin{array}{c}\text { Construções } \\
\text { para } \\
\text { entidades } \\
\text { públicas }\end{array}$ & $\begin{array}{c}\text { Receita } \\
\text { operacional } \\
\text { líquida }\end{array}$ \\
\hline & \multicolumn{2}{|c|}{1.000} & \multicolumn{7}{|c|}{1.000 .000} \\
\hline 2008 & 57 & 1.806 & 25.718 & 38.725 & 132.830 & 163.109 & 158.693 & 68.607 & 154.597 \\
\hline 2009 & 64 & 2.048 & 31.847 & 48.288 & 159.171 & 199.547 & 193.747 & 85.490 & 189.031 \\
\hline
\end{tabular}

Fonte:IBGE (2009, 2010).

Comparando o ano de 2008 com 2009, houve crescimento de $12,28 \%$ no número de empresas e de $13,4 \%$ no de pessoal ocupado. A receita operacional líquida do setor passou de $\mathrm{R} \$ 154,6$ bilhões para $\mathrm{R} \$ 189,03$ bilhões, um crescimento de $22,27 \%$.

Segundo o IBGE (2009), o crescimento na construção civil ocorreu devido à influência positiva de um conjunto de fatores relacionados à dinâmica do setor, como crescimento da renda familiar, que, de acordo com a Pesquisa Mensal de Emprego do IBGE, apresentou um crescimento médio de 3,2\% em 2009; aumento do emprego, com geração de 995,1 mil postos de trabalho em 2009, segundo o Cadastro Geral de Empregados e Desempregados (Caged), do Ministério do Trabalho; e expansão no crédito, em que o total de empréstimos e financiamentos do sistema financeiro nacional passou de $\mathrm{R} \$ 1.227,3$ bilhões em 2008 para R\$ 1.414,4 bilhões em 2009 (IBGE, 2009).

Para o IBGE (2010), maior segurança jurídica, ampliação no prazo, redução nas taxas de juros e expansão da renda vêm aumentando significativamente o valor liberado em crédito imobiliário e o número de unidades financiadas no país. Conforme dados da Câmara Brasileira da Indústria da Construção (Cibic), o valor dos financiamentos com recursos da caderneta de poupança cresceu em termos reais $1.452 \%$ entre 2003 e 2010, passando de R\$ 3,6 bilhões em 2003para R\$ 56 bilhões em 2010. O número de unidades financiadas passou de 36.480 para 421.386 no mesmo período, conforme a Tabela 6 .

Nos financiamentos cuja fonte de recursos foi o Fundo de Garantia por Tempo de Serviço (FGTS), que são destinados à reforma, construção, saneamento, aquisição de imóveis e urbanização, o valor liberado passou de R \$ 6,2 bilhões para R\$ 27,2 bilhões em termos reais no período de 2003 a 2010, e o número de unidades financiadas cresceu $81 \%$ no mesmo período, passando de 246.108 para 444.481

Para Souza (2009), a atividade da construção tem um impacto mais abrangente na economia do que o diretamente visualizado através do produto imobiliário. Existe uma complexa articulação entre os agentes por meio da cadeia produtiva do setor, ligando desde fornecedores de matérias-primas, serviços e outros insumos até atividades que trabalham os produtos imobiliários prontos, como hotéis, aluguéis, administração e consultorias. A identificação das inter-relações entre os agentes da cadeia possibilita dimensionar o setor de forma completa e avaliar o impacto resultante de seu encadeamento para trás e para frente.

Nesse contexto, conforme destacada a grandeza dos investimentos ocorridos no setor da construção civil e a capacidade desse setor em transbordar esses investimentos para os demais setores da economia, a próxima seção abordará o método insumo-produto, utilizado para mensurar o poder multiplicador do setor.

\section{Análise insumo-produto}

Análise insumo-produto é o nome dado a um quadro analítico desenvolvido por Wassily Leontief no final dos anos 1930 com o propósito fundamental de avaliar a interdependência dos setores em uma economia. Atualmente, os conceitos estabelecidos por Leontief são componentes-chave de muitos tipos de análise econômica, e a análise insumo-produto é um dos métodos mais aplicados em economia (MILLER; BLAIR, 2009).

O funcionamento básico da análise é que um grupo de setores produtores de mercadorias (produtos) consome mercadorias de outros setores (insumos) ao longo do processo de produção, em dado período e para uma região geográfica específica (nação, estado, região).

De acordo com Guilhoto (2000), os setores da economia são agrupados em uma matriz em que as linhas registram os fluxos de saídas de produção, mostrando como a produção de um setor de atividade produtiva se distribui entre os demais setores da economia. As colunas da matriz registram as entradas necessárias à produção, mostrando a estrutura de insumos utilizada pelos setores de atividade produtiva. 
Conforme mostra a Figura 1, cada linha da matriz $\mathrm{Z}$ indica o fluxo intersetorial, ou seja, o consumo intermediário de bens e serviços de cada setor. A matriz $\mathrm{Y}$ registra o consumo final, dividido em consumo das famílias, consumo governamental, exportações, formação bruta de capital fixo e variação de estoques. As linhas abaixo das matrizes $\mathrm{Z}$ e $\mathrm{Y}$ registram as despesas com importações, impostos indiretos líquidos e o valor adicionado (remuneração aos serviços dos fatores de produção)

Os totais das colunas e das linhas da matriz (vetor $\mathrm{X}$ e $\mathrm{X}^{\mathrm{T}}$ ) registram a produção total de cada setor e devem ser iguais, indicando o equilíbrio da economia em que as despesas de cada setor são iguais a suas respectivas receitas.

De acordo com Haddad et al. (1989), os principais pressupostos na utilização da metodologia de insumo-produto são:

(a) equilíbrio econômico a dado nível de preços;

(b) inexistência de ilusão monetária por parte dos agentes econômicos;

(c) retornos constantes à escala; e

(d) preços constantes.

Além desses pressupostos, o modelo impõe que cada setor produza somente um produto e que cada produto seja produzido somente por um setor.

Nesse contexto, a economia é dividida em $n$ setores, sendo $\mathrm{Xi}$ o valor bruto da produção do setor i, Yi a parcela da produção do setor i que se destina à demanda final, e Zij a parcela da produção do setor i que se destina ao setor j. Temse o seguinte sistema de equações lineares (Equações 1 a 4):

$$
\begin{array}{cc}
\mathrm{X}_{1}=\mathrm{Z}_{11}+\mathrm{Z}_{12}+\ldots+\mathrm{Z}_{1 n}+\mathrm{Y}_{1} & \text { Eq. } 1 \\
\mathrm{X}_{2}=\mathrm{Z}_{21}+\mathrm{Z}_{22}+\ldots+\mathrm{Z}_{2 n}+\mathrm{Y}_{2} & \text { Eq. } 2 \\
\vdots & \\
\mathrm{X}_{i}=\mathrm{Z}_{i 1}+\mathrm{Z}_{i 2}+\ldots+\mathrm{Z}_{\mathrm{in}}+\mathrm{Y}_{i} & \text { Eq. } 3 \\
\vdots & \\
\mathrm{X}_{n}=\mathrm{Z}_{n 1}+\mathrm{Z}_{n 2}+\ldots+\mathrm{Z}_{n n}+\mathrm{Y}_{n} & \text { Eq. } 4
\end{array}
$$

A partir do referido sistema de equações deriva-se a matriz de coeficientes técnicos $\mathrm{A}$, em que cada elemento $a_{i j}$ é obtido dividindo-se a parcela de insumo absorvida pelo setor $\mathrm{j}$ pelo total da produção desse setor (Equação 5):

$a_{i j}=\frac{Z_{i j}}{X_{j}}$

Eq. 5

Se, por exemplo, o setor 1 opera a um nível de produção exatamente necessário para satisfazer as necessidades de insumos dos $n$ setores, bem como a demanda final, seu nível de produção precisa satisfazer a seguinte Equação 6:

$\mathrm{X}_{1}=\mathrm{a}_{11} \mathrm{X}_{1}+\mathrm{a}_{12} \mathrm{X}_{2}+\ldots+\mathrm{a}_{1 n} \mathrm{X}_{\mathrm{n}}+\mathrm{Y}_{1}$

Eq. 6

Rearranjando a Equação7:

$\left(1-\mathrm{a}_{11}\right) \mathrm{X}_{1}-\mathrm{a}_{12} \mathrm{X}_{2^{-}} \ldots-\mathrm{a}_{1 n} \mathrm{X}_{n}=\mathrm{Y}_{1}$

Analogamente, pode-se estimar a mesma equação para todos os setores, o que permite derivar as equações na forma matricial (Equação 8):

$(\mathrm{I}-\mathrm{A}) \mathrm{X}=\mathrm{Y}$

Eq. 8

Pré-multiplicando os dois lados da Equação 8por:

$(\mathrm{I}-\mathrm{A})^{-1}$ chega-se a Equação 9:

$\mathrm{X}=(\mathrm{I}-\mathrm{A})^{-1} \mathrm{Y}$

Eq. 9

Em que $(\mathrm{I}-\mathrm{A})^{-1}$ é chamada de matriz inversa de Leontief ou matriz tecnológica, e X é a quantidade de produção necessária para atender à demanda intermediária dos $n$ setores e à demanda final Y.

Tabela 6 - Financiamento imobiliário com recursos da caderneta de poupança e FGTS, segundo o número de unidades financiadas e o valor total deflacionado pelo INCC em valores de 2010, Brasil 2003-2010

\begin{tabular}{c|c|c|c|r}
\hline \multirow{2}{*}{ Ano } & \multicolumn{2}{|c|}{ Caderneta de Poupança } & \multicolumn{2}{c}{ FGTS } \\
\cline { 2 - 5 } & Valor Fin. bilhões R\$ & Unidades & Valor Fin. bilhões R\$ & Unidades \\
\hline 2003 & 3,6 & 36.480 & 6,2 & 246.108 \\
\hline 2004 & 4,4 & 53.826 & 5,8 & 267.136 \\
\hline 2005 & 6,8 & 61.121 & 7,6 & 337.767 \\
\hline 2006 & 12,3 & 113.873 & 9,2 & 353.907 \\
\hline 2007 & 22,7 & 195.900 & 8,5 & 315.802 \\
\hline 2008 & 33,3 & 299.746 & 11,5 & 320.477 \\
\hline 2009 & 36,6 & 302.680 & 17,4 & 444.481 \\
\hline 2010 & 56,0 & 421.386 & 27,2 & \\
\hline
\end{tabular}

Fonte: IBGE (2010). 
Figura 1 - Relações fundamentais de insumo-produto

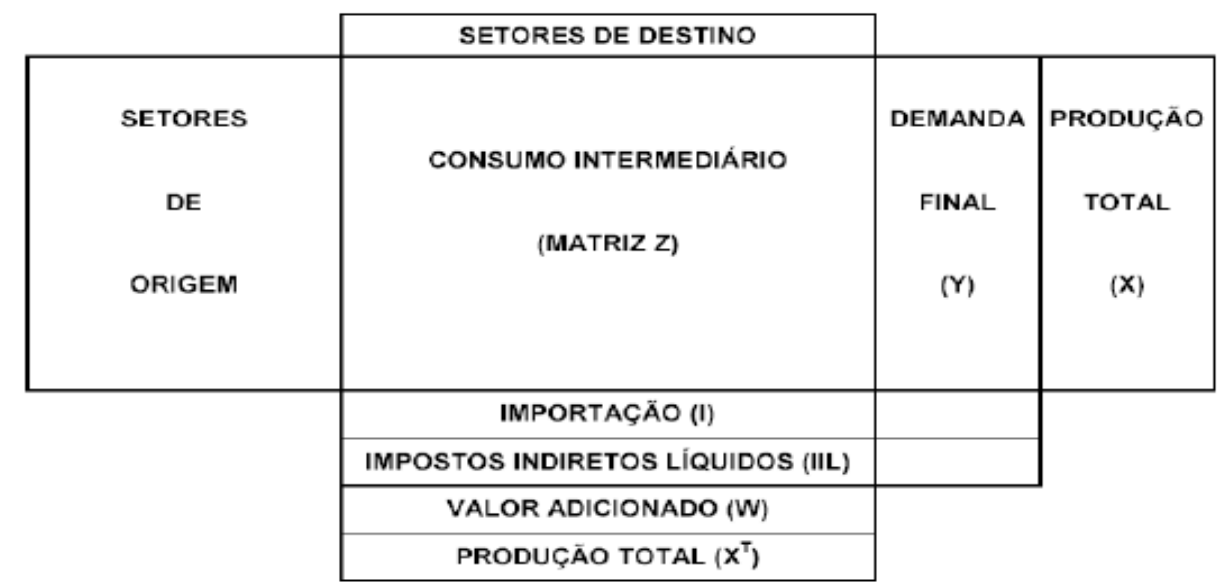

Fonte: adaptado de Guilhoto (2000).

Para Haddad et al.(1989), cada elemento da matriz inversa de Leontief representa a quantidade necessária de insumos diretos e indiretos do setor $i$ por unidade monetária de demanda final à produção do setor $j$. Pela referida matriz, é possível definir o multiplicador de produção para cada setor como sendo a soma de suas colunas.

\section{Multiplicadores e geradores}

Segundo Guilhoto (2000), a partir do modelo básico de Leontief definido anteriormente, pode-se mensurar o impacto que as mudanças ocorridas na demanda final, $\Delta Y$, teriam sobre a produção total, $\Delta X$, conforme a Equação 10:

$\Delta X=(I-A)^{-1} \Delta Y$

Eq. 10

Para se obter o impacto sobre o volume total da produção, somam-se todos os elementos do vetor $\mathrm{X}$. Além do impacto na produção total, haveria o impacto sobre as variáveis (emprego, importações, impostos, salários, valor adicionado e outras), que pode ser mensurado (Equação 11):

$$
\Delta V=v \Delta X
$$

Em que $\Delta V$ é um vetor $(\mathrm{nx} 1)$ que representa o impacto sobre qualquer uma das variáveis anteriormente tratadas, e $\hat{v}$ é uma matriz diagonal (nxn) em que os elementos da diagonal sãoos coeficientes de emprego, importações, salários, valor adicionado, entre outros, que são obtidos dividindo-se o valor utilizado dessas variáveis na produção total pela produção total para cada setor (Equação 12).

$v_{i}=\frac{V_{i}}{X_{i}}$

Eq. 12
Utilizando o emprego como exemplo das variáveis anteriormente mencionadas, pode-se estimar o coeficiente de emprego (Equação 13):

$C P O=P O \cdot \hat{X}^{-1}$

Em que PO é o pessoal ocupado, e X é a produção total.

Para Guilhoto (2000), a partir do coeficiente de emprego CPO, pode-se estimar o gerador de emprego, ou seja, o emprego necessário em todos os setores da economia para atender ao aumento de uma unidade monetária na demanda final de referido setor (Equação 14).

$G V_{i}=\sum_{i=1}^{n} b_{i j} C P O_{i}$

Eq. 14

Em que:

$G V_{i}$ é o impacto direto e indireto sobre o emprego;

$b_{i j}$ é o ij-ésimo elemento da matriz inversa de Leontief; e

$C P O_{i}$ é o coeficiente direto do emprego.

Segundo Miller e Blair (2009), o multiplicador direto e indireto (também conhecido como multiplicador do Tipo 1) para a renda, o emprego, os impostos e o valor adicionado pode ser calculado dividindo-se o gerador pelo coeficiente direto da variável em questão. Utilizando-se novamente o emprego como exemplo, o multiplicador pode ser estimado pela Equação 15:

$M V_{i}=\frac{G V_{i}}{C P O_{i}}$

Eq. 15

O multiplicador de emprego é a quantidade de emprego gerado em toda a economia para cada emprego direto gerado em referido setor. 
Ainda de acordo com Miller e Blair (2009), também se pode estimar o multiplicador induzido (também conhecido como multiplicador Tipo 2 ( $\bar{M}_{I I}$ ), que é o mesmo multiplicador direto e indireto adicionado do efeito do consumo e da renda das famílias. O procedimento para o cálculo é o mesmo do multiplicador direto e indireto; a única alteração é a utilização da matriz inversa de Leontief com a renda e o consumo das famílias endogeneizados (Equação 16):

$$
\bar{M}_{I I}=\frac{\sum_{i=1}^{n+1} C P O_{n+1, i} \bar{b}_{i j}}{C P O_{n+1, j}}
$$

Em que $C P O_{n+1}$ é o coeficiente de emprego com uma linha e uma coluna a mais, e $\bar{b}_{i j}$ é o termo da matriz inversa de Leontief calculada endogeneizando o consumo e a renda das famílias.

Os multiplicadores, direto, indireto e induzido, podem ser estimados também para a renda, as importações, os impostos, o valor adicionado, os salários, entre outras, conforme já mencionado, substituindo-se nos exemplos acima a variável emprego.

\section{Setor-chave}

Segundo Guilhoto (2000), a partir do modelo básico de Leontief e utilizando a metodologia proposta por Hirschman e Rasmussen, é possível determinar quais setores têm maior poder de encadeamento dentro do sistema econômico, calculando os índices de ligação para trás, que fornecem quanto o respectivo setor demanda dos outros setores da economia, e os índices de ligação para frente, que fornecem a quantidade de produtos demandada de outros setores pelo setor.

O índice de ligação para trás, $U_{j}$, ou o poder de dispersão do setor, pode ser estimado pela Equação17:
$\mathrm{Uj}=\left[\mathrm{B}_{* j} / \mathrm{n}\right] / \mathrm{B}^{*}$

Eq. 17

Já o índice de ligação para frente, $U_{i}$, ou sensibilidade da dispersão, pode ser estimado pela Equação18:

$\mathrm{Ui}=\left[\mathrm{B}_{\mathrm{i} *} / \mathrm{n}\right] / \mathrm{B}^{*}$

Eq. 18

Em que B é matriz inversa de Leontief, B* é a média de todos os elementos de $\mathrm{B}, \mathrm{B}_{* \mathrm{j}}$ é a soma de uma coluna típica, $\mathrm{B}_{\mathrm{i}}$ é a soma de uma linha típica, e $n$ é o número de setores.

Os valores maiores do que a unidade para os índices de ligação para trás e para frente em um setor significam que ele apresenta encadeamento acima da média da economia como um todo, portanto são considerados setores-chave para a economia.

A matriz insumo-produto utilizada no presente estudo é estimada para 2008 pelo Núcleo de Economia Regional e Urbana da Universidade de São Paulo (Nereus), desagregada em 42 setores econômicos.

\section{Resultados}

O Programa Minha Casa, Minha Vida (PMCMV), conforme já mencionado, tem como diretrizes básicas a redução do déficit habitacional, a distribuição de renda, a inclusão social e a dinamização do setor da construção civil, além da geração de trabalho e renda.

O presente estudo concentrará seus resultados na questão da geração de emprego, renda, impostos e produção, através da dinamização do setor da construção civil, não abordando questões políticas ou meritórias do programa, como salientado anteriormente. $\mathrm{O}$ setor da construção civil apresenta índices de ligação para trás (HRBL) e para frente (HRFL) abaixo da média dos outros setores da economia, considerando que o valor médio para esses índices é a unidade, conforme mostra a Tabela 7

Tabela 7- Índices de ligação para trás e para frente do setor da construção civil, Brasil 1990-2008

\begin{tabular}{c|c|c|c|c|c}
\hline ÍNDICES & $\mathbf{1 9 9 0}$ & $\mathbf{1 9 9 5}$ & $\mathbf{2 0 0 0}$ & $\mathbf{2 0 0 5}$ & $\mathbf{2 0 0 8}$ \\
\hline HRBL & 0,9078 & 0,8437 & 0,9199 & 0,8788 & 0,8951 \\
HRFL & 0,6465 & 0,6684 & 0,6638 & 0,6376 & 0,6465 \\
\hline
\end{tabular}

Nota: Para os anos de 1990, 1995, 2000 e 2005, utilizou-se a matriz insumo-produto divulgada pelo IBGE. Para 2008, a projeção feita pelo Nereus. 
O referido setor apresenta índices mais elevados de ligação para trás, o que indica que é mais forte como demandante de insumos do que como ofertante de produtos para os outros setores da economia. No ano de 2000 era o trigésimo no ranking dos setores com índice de ligação para trás mais elevados e o trigésimo segundo no que se refere aos índices para frente. Em 2008 sua posição no ranking dos índices de ligação para trás continua a mesma, enquanto no índice para frente caiu uma colocação.

Considerando a matriz insumo-produto para 2008, o setor da construção civil apresentou um gerador induzido de produção de 1,76 , isto é, para cada real acrescido na demanda final do setor da construção civil, torna-se necessário que a produção da economia como um todo aumente em $\mathrm{R} \$ 1,76$, inclusive o setor de construção civil (Anexo 1).

Nesse contexto, conforme a previsão do Ministério das Cidades, o investimento de R $\$ 125,7$ bilhões no PMCMV para o período 2011-2014 terá um efeito na produção da economia de $\mathrm{R} \$ 221,2$ bilhões, que representa $6 \%$ do valor do PIB de $2010^{2}$. Considerando o período de quatro anos, isso equivale a, aproximadamente, $1,5 \%$ do PIB nos períodos subsequentes.

No que diz respeito às remunerações pagas (salários e contribuições sociais efetivas), o gerador direto e indireto de renda mostrou que, para cada real acrescido na demanda final do setor da construção civil, as remunerações pagas aumentam em $\mathrm{R} \$ 0,33$. Quando se inclui o consumo e a renda das famílias (gerador induzido), esse valor aumenta para $\mathrm{R} \$ 0,50$, conforme a Tabela 8 .

Ante o exposto, os R \$ 125,7 bilhões previstos em investimentos pelo PMCMV no período 2011 2014 aumentarão a remuneração paga aos trabalhadores em cerca de $\mathrm{R} \$ 63,5$ bilhões, diluídos no período de aproximadamente quatro anos.

O gerador induzido de emprego mostra quantos postos de trabalho serão necessários na economia para atender ao aumento de um milhão de reais na demanda final de referido setor, considerando as famílias. No que tange ao investimento previsto pelo PMCMV no setor da construção civil, o aumento será de cerca de sete milhões de novos postos de trabalho em toda a economia, no período subsequente, inclusive o setor da construção civil.
O PMCMV apresenta um considerável valor em subsídios, cerca de R $\$ 72,6$ bilhões previstos para 2011 e os próximos três anos, por isso uma análise interessante é a do gerador de impostos. De acordo com o gerador induzido de impostos estimado para o setor, para cada real acrescido na demanda final, $\mathrm{R} \$ 0,16$ volta para os cofres públicos em impostos. (considerando o Imposto sobre Comercialização de Mercadorias e Serviços - ICMS $^{3}$, Imposto sobre Produtos Industrializados - IPI e o Imposto sobre Importação), ou seja, dos $\mathrm{R} \$ 125,7$ bilhões previstos de investimentos, $\mathrm{R} \$ 20,11$ bilhões voltarão para o Estado em impostos.

A Tabela 8, além dos geradores, também mostra os multiplicadores. A interpretação dos multiplicadores é diferente da dos geradores. No caso do emprego, pode-se dizer que o multiplicador induzido mostra quantos empregos são gerados na economia (incluindo as famílias) para cada emprego gerado na construção civil. Em outras palavras, considerando a matriz insumoproduto para 2008, para cada emprego gerado na construção civil, 1,95 empregos (considerando o multiplicador induzido) serão gerados na economia. Para a renda e os impostos, a interpretação é a mesma.

Diante dos resultados obtidos, constatou-se que, quando comparado com outros setores da economia, o setor da construção civil não é o que apresenta maior transbordamento para os outros setores, no entanto seus impactos são consideráveis, principalmente na geração de empregos

\section{Conclusão}

Considerando o objetivo proposto pelo presente artigo, de identificar os impactos do PMCMV na economia brasileira, principalmente no que diz respeito à produção, ao emprego e à renda, pode-se concluir que o setor da construção civil mostrou desempenho abaixo da média dos outros setores da economia, tanto no que se refere às ligações para trás, demandando insumos, quanto para a frente, ofertando produtos. Quanto ao multiplicador direto e indireto da produção, a construção civil foi o trigésimo setor no ranking dos 42 setores da economia, não obstante apresente bons resultados no que se refere à geração de empregos.

\footnotetext{
${ }^{2}$ Segundo o IBGE, o PIB em 2010 foi de R\$ 3,675 trilhões. A comparação com o PIB não foi feita com o intuito de projeção de impacto, mas sim para dar uma ideia da grandeza dos valores.
}

\footnotetext{
${ }^{3}$ Nacional + importado.
} 
Tabela 8 - Multiplicadores e geradores de renda, emprego e impostos, Brasil 2008

\begin{tabular}{l|c|r|c}
\hline Geradores e Multiplicadores & Renda & Emprego & Impostos \\
\hline Gerador direto & 0,18888 & 28,4300 & 0,03837 \\
Gerador direto e indireto & 0,33235 & 38,6468 & 0,07269 \\
Gerador induzido & 0,50560 & 55,5641 & 0,16062 \\
Multiplicador direto e indireto & 1,75951 & 1,3595 & 1,89447 \\
Multiplicador induzido & 2,67677 & 1,9546 & 4,18613 \\
\hline
\end{tabular}

No entanto, devido ao vultoso valor previsto para o investimento pelo PMCMV, os impactos serão significativos. Na produção, nos próximos quatro anos, o impacto deverá ser de aproximadamente $6 \%$ do PIB em valores de 2010. No emprego, estima-se a criação de cerca de sete milhões de novos postos de trabalho e um aumento de cerca de $\mathrm{R} \$ 63$ milhões na renda direta e indiretamente gerada pelo setor, e paga aos trabalhadores ao longo dos quatro anos e períodos subsequentes. Outra constatação relevante diz respeito ao subsídio concedido nos financiamentos do programa, considerando que se espera que $16 \%$ do total financiado retorne aos cofres públicos como impostos.

O impacto estimado na economia, concomitantemente ao impacto social da criação de cerca de dois milhões de novas residências para famílias de baixa renda, demonstra que o PMCMV pode cumprir, considerando os investimentos previstos para o período 2011-2014, suas diretrizes básicas de geração de trabalho, renda e redução do déficit habitacional, o que não tira a responsabilidade dos governantes de geri-lo de forma eficiente, para que o programa alcance os resultados esperados.

O presente artigo não tem como objetivo esgotar o assunto em discussão, mas trazer uma leitura do PMCMV que não tem sido abordada com frequência nas discussões acerca do tema, em que a questão social tem sido predominante.

A principal limitação do trabalho ao utilizar o método de insumo-produto é o fato de se trabalhar com relações lineares e proporções fixas, e, por conseguinte, retornos constantes de escala e preços constantes. Esses fatores podem comprometer os resultados, caso o aumento da demanda pressione os preços dos fatores de produção, principalmente o valor dos terrenos e a mão de obra. No entanto, mesmo com algumas limitações, o método é amplamente aceito em estudos de análise de impacto, como o caso do presente artigo.

\section{Referências}

BRASIL. Lei n. 12.424, de 7 de julho de 2009, dispõe sobre o Programa Minha Casa Minha Vida - PMCMV e a regularização fundiária de assentamentos localizados em áreas urbanas. Diário Oficial da União,Brasília, 8 de julho de 2009.

BRASIL. Lei n. 11.977, de 16 de junho de 2011, altera a Lei n.12424, de 7 de julho de 2009, que dispõe sobre o Programa Minha Casa Minha Vida - PMCMV e a regularização fundiária de assentamentos localizados em áreas urbanas. Diário Oficial da União,Brasília, 17 de junho de 2011.

FERREIRA, F. P. Demanda Habitacional: uma metodologia de acompanhamento e previsão para as regiões administrativas do distrito federal. In: ENCONTRO NACIONAL DE ESTUDOS POPULACIONAIS, 14., Caxambu, MG, 2004. Anais... Caxambu: ABEP, 2004.

FURTADO, B. A.; LIMA NETO, V. C.; KRAUSE, C. Estimativas do Déficit Habitacional Brasileiro (2007-2011) Por Municípios (2010). Brasília, DF: IPEA, 2013. 20 p. (Notas Técnicas, 1).

GONÇALVES, R. R. O Déficit Habitacional Brasileiro Um Mapeamento Por Unidades da Federação e Por Níveis de Renda Domiciliar. In: Texto Para Discussão 559. Rio de Janeiro: IPEA, 1998.

GUILHOTO, J. J. M. Leontief e InsumoProduto: antecedentes, princípios e evolução. Piracicaba: ESALQ, Depto de Economia, Administração e Sociologia, 2000. 64 p. (Seminários da Pós-Graduação, 15).

HADDAD, P. R.et al.Economia Regional: teorias e métodos de análise. Fortaleza: Banco do Nordeste, 1989.

INSTITUTO BRASILEIRO DE GEOGRAFIA E ESTATÍSTICA. Classificação nacional de atividades econômicas: versão 2.0. IBGE: Rio de Janeiro. 2007.

INSTITUTO BRASILEIRO DE GEOGRAFIA E ESTATÍSTICA. Pesquisa Anual da Construção Civil 2009. Rio de Janeiro: IBGE, 2009. v. 19. 
INSTITUTO BRASILEIRO DE GEOGRAFIA E ESTATÍSTICA. Pesquisa Anual da Construção Civil 2010. Rio de Janeiro: IBGE, 2010. v. 20.

MAGALHÃES, I. S. Programa Minha Casa, Minha Vida 2: novo momento, características e agentes. In: ENCONTRO NACIONAL DA INDÚSTRIA DA CONSTRUÇÃO, 83., São Paulo, 2011.Anais...São Paulo, 2011.

MILLER, R. E.; BLAIR, P. D. Input-Output Analysis: foundations and extensions.New Jersey: Prentice Hall, 2009.

\section{MINISTÉRIO DAS CIDADES. Déficit}

Habitacional no Brasil 2008. Elaborado por: Fundação João Pinheiro, Centro de Estatística e Informações. Brasília, DF: Ministério das Cidades, 2011. 140 p.

POLENSKE, K. R.; SIVITANIDES, P. Linkages in the Construction Sector.In: DEPARTMENT OF URBAN STUDIES AND PLANNING - MIT.The Annals of Regional Science.Cambridge, MA: 1989.
SOUZA, V. V. Evolução do Complexo da Construção Civil Entre 2000 e 2005: uma abordagem de insumo produto. Porto Alegre, 2009. 90 f. Dissertação (Mestrado em Economia) Faculdade de Administração, Contabilidade e Economia, Pontifícia Universidade Católica Rio Grande do Sul, Porto Alegre, 2009.

TEIXEIRA, L. P.; CARVALHO, F. M. A. A Construção Civil Como Instrumento do Desenvolvimento da Economia Brasileira. Revista Paranaense de Desenvolvimento, v. 109, p. 7-25, 2005.

TEIXEIRA, L. P.; GOMES, M. F. M.; SILVA, A. B. O. Construção Civil Mineira: dinâmica e importância para a economia estadual.

RevistaBrasileira de Gestão e Desenvolvimento Regional, v. 7, p. 69-95, 2011.

UN-HABITAT.Scaling-Up Affordable Housing Supply in Brazil:the House My Life Programme.Nairobi : UN-Habitat, 2013. v. 2, Housing Practice Series.

VASCONCELOS, J. R.; CÂNDIDO JUNIOR, J. O. O Problema Habitacional no Brasil: déficit financiamento e perspectivas. Texto Para Discussão 410.Brasília: Ipea, 1996. 
ANEXO 1 - Multiplicador de produção direta e indireta e ranking, Brasil 2008

\begin{tabular}{|c|c|c|c|c|c|}
\hline & SETOR & $\begin{array}{l}\text { Gerador direto } \\
\text { de produção }\end{array}$ & Ranking & $\begin{array}{l}\text { Gerador direto } \\
\text { e indireto de } \\
\text { produção }\end{array}$ & Ranking \\
\hline 1 & AGROPECUÁRIA & 0,37 & 36 & 1,73 & 31 \\
\hline 2 & EXTRAT. MINERAL & 0,40 & 34 & 1,72 & 32 \\
\hline 3 & PETRÓLEO E GÁS & 0,42 & 29 & 1,71 & 34 \\
\hline 4 & MINERAL Ñ METÁLICO & 0,53 & 20 & 1,97 & 22 \\
\hline 5 & SIDERURGIA & 0,56 & 18 & 2,02 & 19 \\
\hline 6 & METALURG. Ñ FERROSOS & 0,59 & 14 & 2,08 & 16 \\
\hline 7 & OUTROS METALÚRGICOS & 0,51 & 24 & 1,97 & 21 \\
\hline 8 & MÁQUINAS E EQUIP. & 0,56 & 16 & 2,07 & 17 \\
\hline 9 & MATERIAL ELÉTRICO & 0,57 & 15 & 2,08 & 15 \\
\hline 10 & EQUIP. ELETRÔNICOS & 0,55 & 19 & 2,02 & 20 \\
\hline 11 & AUTOM./CAM/ÔNIBUS & 0,70 & 6 & 2,37 & 6 \\
\hline 12 & PEÇAS E OUT. VEÍCULOS & 0,59 & 13 & 2,16 & 11 \\
\hline 13 & MADEIRA E MOBILIÁRIO & 0,50 & 25 & 1,91 & 27 \\
\hline 14 & CELULOSE, PAPEL E GRÁF. & 0,52 & 22 & 1,95 & 25 \\
\hline 15 & IND. DA BORRACHA & 0,53 & 21 & 2,06 & 18 \\
\hline 16 & ELEMENTOS QUÍMICOS & 0,60 & 11 & 2,09 & 14 \\
\hline 17 & REFINO DO PETRÓLEO & 0,70 & 7 & 2,31 & 7 \\
\hline 18 & QUÍMICOS DIVERSOS & 0,61 & 9 & 2,19 & 9 \\
\hline 19 & FARMÁC. E VETERINÁRIA & 0,49 & 26 & 1,93 & 26 \\
\hline 20 & ARTIGOS PLÁSTICOS & 0,56 & 17 & 2,15 & 12 \\
\hline 21 & IND. TÊXTIL & 0,51 & 23 & 1,95 & 24 \\
\hline 22 & ARTIGOS DO VESTUÁRIO & 0,49 & 27 & 1,90 & 28 \\
\hline 23 & FABRICAÇÃO CALÇADOS & 0,60 & 12 & 2,19 & 10 \\
\hline 24 & INDÚSTRIA DO CAFÉ & 0,80 & 2 & 2,50 & 2 \\
\hline 25 & BENEF. PROD. VEGETAIS & 0,76 & 5 & 2,50 & 3 \\
\hline 26 & ABATE DE ANIMAIS & 0,78 & 4 & 2,42 & 5 \\
\hline 27 & INDÚSTRIA DE LATICÍNIOS & 0,78 & 3 & 2,46 & 4 \\
\hline 28 & FABRICAÇÃO DE AÇÚCAR & 0,61 & 10 & 2,11 & 13 \\
\hline 29 & FAB. ÓLEOS VEGETAIS & 0,91 & 1 & 2,74 & 1 \\
\hline 30 & OUTROS PROD. ALIMENT. & 0,63 & 8 & 2,21 & 8 \\
\hline 31 & INDÚSTRIAS DIVERSAS & 0,49 & 28 & 1,95 & 23 \\
\hline 32 & S.I.U.P. & 0,41 & 32 & 1,71 & 33 \\
\hline 33 & CONSTRUÇÃO CIVIL & 0,41 & 33 & 1,76 & 30 \\
\hline 34 & COMÉRCIO & 0,25 & 41 & 1,42 & 41 \\
\hline 35 & TRANSPORTES & 0,42 & 30 & 1,79 & 29 \\
\hline 36 & COMUNICAÇÕES & 0,41 & 31 & 1,69 & 35 \\
\hline 37 & INSTITUIÇÕES FINANCEIRAS & 0,32 & 38 & 1,52 & 39 \\
\hline 38 & SERV. PREST. À FAMÍLIA & 0,37 & 35 & 1,68 & 36 \\
\hline 39 & SERV. PREST. À EMPRESA & 0,33 & 37 & 1,56 & 38 \\
\hline 40 & ALUGUEL DE IMÓVEIS & 0,07 & 42 & 1,11 & 42 \\
\hline 41 & ADMINISTRAÇÃO PÚBLICA & 0,29 & 40 & 1,49 & 40 \\
\hline 42 & SERV. PRIV. Ñ MERCANTIS & 0,32 & 39 & 1,58 & 37 \\
\hline
\end{tabular}

188 Gonçalves Junior, C. A.; Dutra, R. de L.; Lopes, R. L.; Rodrigues, R. L. 


\section{Carlos Alberto Gonçalves Junior}

Departamento de Economia, Centro de Ciências Sociais Aplicadas | Universidade Estadual do Oeste do Paraná | Rua da Faculdade, 645 , Jard im Santa Maria, Campus Toledo | Toledo - PR - Brasil | Tel.: (45) 3379-7187 | E-mail: carlosalbertojr@hotmail.com

\section{Ricardo de Lemos Dutra}

Mestre em Desenvolvimento Regional e Agronegócios | Universidade Estadual do Oeste do Paraná | Tel.: (45) 3278-2002 |

Email: ricardo_rld16@hotmail.com

\section{Ricardo Luis Lopes}

Departamento de Economia, Centro de Ciências Sociais Aplicadas | Universidade Estadual de Maringá | Av. Colombo, 5790, Jardim Universitário | Maringá - PR - Brasil | CEP 87020-900 | Tel.: (44) 3011-4905 | Email:rllopes@uem.br

\section{Rossana Lott Rodrigues}

Departamento de Economia, Centro de Estudos Sociais Aplicados | Universidade Estadual de Londrina | Rodovia Celso Garcia Cid, Km 380 Campus Universitário | Londrina - PR - Brasil | Caixa Postal 10.011 | CEP 86057-970 | Tel.: (43) 3371-000 Ramal 4255 |

Email: rlott@sercomtel.com.br

\section{Revista Ambiente Construído}

Associação Nacional de Tecnologia do Ambiente Construído

Av. Osvaldo Aranha, $99-3^{\circ}$ andar, Centro

Porto Alegre - RS - Brasil

CEP $90035-190$

Telefone: +55 (51) 3308-4084

Fax: +55 (51) 3308-4054

www.seer.ufrgs.br/ambienteconstruido

E-mail: ambienteconstruido@ufrgs.br 